\title{
Evaluation of Risk Factors of Diabetes Mellitus among Out-patients in two Nigerian Secondary Health Facilities
}

\author{
Chinonyerem Iheanacho ${ }^{1}$, Doyin Osoba ${ }^{2}$, and Uchenna Eze ${ }^{2}$ \\ ${ }^{1}$ Affiliation not available \\ ${ }^{2}$ Olabisi Onabanjo University
}

April 27, 2020

\begin{abstract}
Aim: Prevention of type 2 diabetes is enabled by identification and effective management of risk factors. The study was conducted to evaluate the risk factors associated with the development of type 2 diabetes. Methods: A cross-sectional survey was conducted on persons without diabetes in two secondary hospitals using Canadian diabetes risk assessment questionnaire. Data analysis was done using SPSS version 18. Result: A total of 300 respondents participated in the study and 160 (53.3\%) were at high risk of developing type 2 diabetes. From the risk evaluation, males (62.5\%), overweight (65.1\%) and obese $(82.6 \%)$ participants; were at high risk for type 2 diabetes. Others found to be at high risk were; respondents with high waist circumference $(55.6 \%)$, respondents who did not exercise $(77.0 \%)$, those who did not eat fruits and vegetable daily $(54.4 \%$ ), those with high blood pressure (67.5\%) and those who have had raised blood sugar in the past (71.0\%). Conclusion: Majority of the study participants was at high risk for type 2 diabetes and male participants had higher risks than their female counterparts. Other socio-demographic factors also presented major risks for type 2 diabetes.
\end{abstract}

\section{Hosted file}

DIABETES_EVALUATION.docx available at https://authorea.com/users/315850/articles/446075-evaluationof-risk-factors-of-diabetes-mellitus-among-out-patients-in-two-nigerian-secondary-healthfacilities 